\title{
Short-term and Long-term Retention of Vocabulary through Authentic Subtitled Videos
}

\author{
Nader Asadi Aidinlou \\ Department of English Language and Linguistics, Islamic Azad University Ahar Brach, Ahar-Tabriz 2km.Ahar, East Azarbaijan, Iran \\ E-mail: naderasadi@yahoo.com
}

Alireza Moradinejad (Corresponding author)

Eslamic Azad University of Telesh, Iran, Guilan, Talesh

E-mail: alireza_moradinejad@yahoo.com

Doi:10.7575/aiac.alls.v.7n.5p.14

URL: http://dx.doi.org/10.7575/aiac.alls.v.7n.5p.14
Received: 01/05/2016

Accepted: 04/07/2016

\begin{abstract}
The current study made an attempt to compare the impacts of teaching authentic materials through traditional techniques with teaching authentic materials through authentic use, where students in the experimental group were taught new vocabulary items of subtitles through watching subtitled videos, and control group were taught the same vocabulary items from subtitles using traditional instruction of vocabulary. The participants of the study consisted of 36 Iranian students from both genders. In order to ensure the homogeneity of the participants, Oxford Placement Test (2004) was administered. Then they were randomly put into two groups (18 students in each group). Immediately after the study and three weeks after the study vocabulary tests were administered to the both groups. The results indicated that the students of control group outperformed in short-term retention. However, the experimental group outperformed in long-term retention, indicating the superiority of learning vocabulary through watching subtitled videos in long-term retention of vocabulary. As many learners do not develop long-term mastery of the vocabulary, teaching vocabulary items through watching videos with subtitles can help them store and retrieve vocabulary items better.
\end{abstract}

Keywords: Authentic materials, Subtitled videos, Subtitles, Long-term retention, Short-term Retention

\section{Introduction}

For many decades, vocabulary learning was not important and it has been one of the areas of language teaching that was largely neglected. Practitioners used to let learners be responsible for vocabulary learning. Fortunately, nowadays, vocabulary learning is claimed to be a priority in second language acquisition and teaching vocabulary is stressed. Furthermore, "lexical approaches in language teaching reflect a belief in the centrality of lexicon to language structure, second language learning, and language use"(Richards \& Rodgers, p.132). On the other hand, vocabulary instruction through authentic use of materials has been scarce, since teachers find it difficult to make an appropriate and authentic use of these materials. Authentic materials make it possible for learners "to interact with the real language and content rather than the form" (Berardo, 2006, p.62). Since technology and audiovisual equipments provide a range of options for creating a realistic simulation of the real world, "electronic applications are often used for implementing authentic learning environments" (Gulikers, Bastiaens \& Martens, 2005, p.510). Among electronic equipments, video clips perform an important role in leaning vocabulary. In addition, interesting videos "can simply provide a welcome break from the rigors of more traditional study" (Shrosbree, 2008, p.76). However, learning vocabulary through watching video clips can be very demanding because it seems to "rule out the use of the 'monitor' through lack of time" (Vanderplank, 1988, p.276). In effect, "badly handled video activities can be just as de-motivating. Here is where the use of subtitles can play a key role in the foreign language class, to help overcome this problem" (Zanon, 2007, p.6). In fact, "for many learners, text provides a conscious monitoring of the speech" (Vanderplank, 1988, p.277). In sum, Zanon (2007) contends that

authentic video and subtitles can precisely play an important role to help learners increase and strengthen their foreign language vocabulary, given the appropriate guidance. Any well-prepared learning task using subtitles in authentic video clips [...] will encourage a better understanding and acquisition of new vocabulary; new and old lexical items will enter the students' minds more easily given the motivating and comprehensive atmosphere provided by this familiar type of audio-visual environment (Zanon, 2007, p.7)

\subsection{Definition of Authentic Materials}

The concept of "authenticity was popularized in the 1980s and many scholars started to identify various degrees of authenticity" (Shomoossi \& Ketabi, 2007, p.152). In terms of materials, authenticity "can be clearly defined, but when we go beyond the text, authenticity is very much a matter of interpretation" (Taylor, 1994, p.3). For some scholars, 
"materials generated by native speakers and for native speakers" are regarded as authentic (Rogers \& Medley, 1988; cited in Shomoossi \& Ketabi, 2007, p.150). However, attempts have been made to adopt a broader perspective on authenticity. Other aspects such as "the authenticity of situation in which the language is produced as well as [...] the source of the sample and the purpose of the speakers" were also determined (Shomoossi \& Ketabi, 2007, P.150)

Two basic types of authenticity was always identified by scholars: some think of authenticity of text while others think of authenticity of the use to which it is put (Taylor, 1994). For example, MacDonald (2006) contends that "authenticity is an attribute of language, text or materials. It refers to a correspondence between 'pedagogic' language, texts or materials and 'real world' language, texts or artefacts" (p.2).

Breen, however, identified authenticity of four types:

1) Authenticity of the texts which we may use as input data for our students;

2) Authenticity of the learners' own interpretations of such texts;

3) Authenticity of tasks conducive to language learning;

4) Authenticity of the actual social situation of the classroom language. (Breen, 1985, p.61)

Finally, in 1994, Taylor identified three different types of authenticity, which he argued that are not clearly distinguished:

1) Authenticity of language,

2) Authenticity of task,

3) Authenticity of situation.

Many authors supporting the use of authentic materials in language teaching have valued the idea of exposure, that is, "the benefit students get from being exposed to the language in authentic materials" (Al Azri \& Al-Rashdi, 2014, p.249). For example, Berardo (2006) argues that "one of the main ideas of using authentic materials in the classroom is to "expose" the learner to as much real language as possible" (p.64). In fact, through using authentic materials "the possibility of incidental vocabulary learning through repeated exposure" is highlighted (Gu, 2003, p.4).

\subsection{Advantages of using authentic materials}

Many studies and authors encourage the use of authentic materials in language teaching. Most of these studies emphasized a direct and positive relationship between using authentic materials in language classrooms and motivation (e.g. Al Azri \& Al-Rashdi, 2014; Guariento \& Morley, 2001; Peacock, 1997). However, there are some other benefits from the use of authentic materials, which are as follows:

- Authentic materials "give the learner the feeling that he or she is learning the 'real' language; that they are in touch with a living entity, the target language as it is used by the community which speaks it" (Guariento \& Morley, 2001, p.347).

- Authentic materials "will bring them [learners] closer to the target language culture, and therefore this will result in them making the learning process overall an even more enjoyable and thus, motivating" (Al Azri \& Al-Rashdi, 2014, p.249).

- Authenticity "prepares the learners for the real world situations in terms of using the target language" (Al Azri \& Al-Rashdi, 2014, p.250).

- Authentic materials "encourage learners to learn a particular language successfully, because they notice they are dealing with the language in real life" (Al Azri \& Al-Rashdi, 2014, p.253).

- Appropriate authentic materials may increase "learners' levels of on-task behaviour, concentration, and involvement in the target activity more than artificial materials (Peacock, 1997, p.152).

- "One of the main reason for using authentic materials in the classroom is once outside the "safe", controlled language learning environment, the learner will not encounter the artificial language of the classroom but the real world and language how it is really used" (Berardo, 2006, p.66).

To Berardo (2006), the main advantages of using authentic materials in the classroom are as follows:

- having a positive effect on student motivation;

- giving authentic cultural information;

- exposing students to real language;

- relating more closely to students' needs;

- supporting a more creative approach to teaching. (p.64)

\subsection{Disadvantages of using authentic materials}

Authentic materials also bring some problems. For example, "they present real language that is not graded nor simplified, and spoken at a normal speed" (Zanon, 2007, p.5). Moreover, most authentic materials are available and suitable for post-intermediate levels. In other words, at lower levels authentic materials prevent learners from responding meaningfully, cause frustration, confusion, and decrease motivation (Guariento \& Morley, 2001). In addition, for learners authentic materials, though more motivating, are less interesting in comparison with non-authentic materials (Peacock, 1997). 
Despite the abovementioned disadvantages, the advantages of using authentic materials in teaching language classrooms outweigh the disadvantages.

\subsection{Video clips as authentic materials}

Different kinds of authentic materials can be used in the classroom. They include magazines, newspapers, sitcoms, TV programs, short films, news, movies, cartoons, and songs. Among authentic materials, video clips from mass media are more appealing "because of their realistic, ready-to-use language and relevance to learners' mindsets and experiences" (Hwang, 2005, p.2). Furthermore, "video allows learners to see the context of the discourse and the speaker's body language as well as other visual aids to comprehension" (Shrosbree, 2008, p.75).

Generally, there are two types of video clips: (1) instructional videos specifically created to teach foreign languages, (2) authentic video materials, such as films, TV series, commercials, etc., created for native speakers of the language. Despite their difficulty, authentic video clips are in fact very beneficial to use in the language class "since students can profit more efficiently from this type of input, given its presentation of real (not manipulated) and complete communicative situations, that is what learners really need in real life" (Zanon, 2007, p.5)

Gulikers, Bastiaens and Martens (2005) argue that "the use of multimedia creates possibilities for implementing new ideas about important learning activities like discovery learning and active exploration, which are important in authentic learning" (p.512). The subtitled video is tremendously valuable since it combines sounds, images, text as well as information about socio-cultural habits and culture, which makes the video "a very comprehensible tool for teaching vocabulary to foreign language students" (Zanon, 2007, p.5). In addition, video clips "fit into the informal environment of acquisition, to provide comprehensible input with the emphasis on the message rather than on the form, to rely on attitudinal and motivational factors (Vanderplank, 1988, p.276). Finally, "foreign language words are learned better when directly associated with appropriate nonverbal referents (objects, events, emotions, context, etc.); this efficient association can only be found in real life or in authentic video" (Zanon, 2007, p.8).

In terms of selection of authentic materials, many authors have argued that appropriate materials need to be selected by teachers (e.g. Hwang, 2005; Şarapl, 2011). In fact, "teachers need to "shop around" and make selections based on their own and their students' interests, because only interests can lead to a sustainable passion for this practice over the long haul" (Hwang, 2005, p.8).

There is always this concern that authentic materials particularly authentic video clips are not perfectly comprehensible. However, Guariento and Morley (2001) state that partial comprehension of materials is not necessarily problematic because this is also common in real life situations.

One of the most useful kinds of video clips is sitcom. Sitcoms are audiovisual and engage learners. In order for audiovisual clips to be successful in developing foreign language skills, they are clear and interesting and motivate and engage learners.

\subsection{Subtitles and language learning}

It is worth mentioning that authentic materials such as video clips can also be problematic because the language used is not graded or simplified. Nevertheless, this problem can be avoided through subtitles (Zanon, 2007). The beneficial effect of subtitles in language learning has recently been of interest to many scholars and many studies have investigated the effects of subtitles in vocabulary learning (e.g. Lertola, 2012; Sabouri, Zohrabi \& Osbouei, 2015; Zarei, 2009).

Zanon (2007) distinguishes three types of combinations of audio and subtitles:

1) standard subtitles (the combination of foreign language audio and mother tongue captions),

2) bimodal subtitles (foreign language audio combined with foreign language subtitles),

3) reversed subtitles (mother tongue audio combined with foreign language captions).

He further argues that, among the three types of subtitles, in classroom activities, the bimodal one, also called intralingual, is more common. He also contends that

text in the form of subtitles helps learners monitor a speech that would probably be lost otherwise. In fact, while TV programs and films that are not subtitled can create a high level of insecurity and anxiety in students, the incorporation of subtitles provides instant feedback and a positive reinforcement that contributes to create a feeling of confidence in learners that can help them feel ready and motivated to watch foreign television, films, etc., with or without the support of subtitles in the near future (p.6)

It should be mentioned that subtitles have sometimes been regarded as distracting and intrusive (Zanon, 2006; Vanderplank, 1988) and as "tending to slow down the development of listening skills, because they are seen to make learners rely on the text rather than on the stream of speech" (Zanon, 2006, p.42). Moreover, many consider audiovisual input ridiculous-"they do not understand why should they make efforts to read something when they could just hear it in their own language" (Zanon, 2006, p.42). Nonetheless, many scholars argue that not only are not subtitles a source of distraction and laziness, but they help the language acquisition process. They do so "by providing language learners with the key to massive quantities of authentic and comprehensible language input" (Vanderplank, 1988, p.273). Moreover, subtitles make learners conscious of unfamiliar vocabulary in the stream of speech. Regarding psychology, subtitles provide instant feedback and as a result positive reinforcement for learning which in turn leads to building up the learner's confidence (ibid). 
The triple connection between image, sound and text in subtitled video clips creates "visual associations in memory for vocabulary learning [...] this type of connection generally encourages greater retention in lexical terms. This mnemonic power of images is [...] enhanced by the presence of sound and text together" (Zanon, 2007, p.7). This connection facilitates vocabulary learning since video is able "to improve the building of a mental image, to create a curiosity that leads to intense focusing" (ibid). Moreover, this combination results in focusing on the correct form of new, technical and unfamiliar words (Vanderplank, 1988). In other words, "subtitled videos representing words and pictures in oral and visual form are more probable to activate both coding systems in the processing than words or pictures alone" (Harji, Woods \& Alavi, 2010, p.38).

Zanon (2006) argues that learners use subtitles for a purpose, that is, as a support for comprehension of new vocabulary items. Perfect understanding of every word being used is not the purpose. In fact, subtitles make learners feel safe and confident. In sum

All things considered, the use of video subtitles provides a dynamic and rich source of communicative language in use. It is dynamic because all languages are in constant change, never fixed [...]. With the appropriate guidance and training, subtitles give learners a subjective support that they need many times to feel more comfortable and motivated when learning a foreign language, and an objective aid in terms of recognition, maintenance, and production of new and already known linguistic items, thanks to the multiple associations they provide, together with the context and the environment in which they appear. (Zanon, 2006, p.45)

Considering what is mentioned, the present study attempts to indicate that, among different ways of learning and teaching vocabulary, learning vocabulary through watching subtitled video clips, that is, authentic use of authentic materials will lead to a better short term and long-term retention. Consequently, the research hypotheses are as follows:

1) Teaching authentic vocabulary through authentic subtitled video clips leads to a better short-term retention of vocabulary compared with traditional method in an EFL context.

2) Teaching authentic vocabulary through authentic subtitled video clips leads to a better long-term retention of vocabulary compared with traditional method in an EFL context.

\section{Method}

\subsection{Participants}

Students, who participated in this study, included 36 EFL learners. They were divided into two equal-sized groups: one as treatment $(\mathrm{N}=18)$ and another as control $(\mathrm{N}=18)$. The participants were taking a vocabulary course. They had already studied English for about 10 years. The participants chosen in the present study were at advanced level since as it was discussed above authentic materials are appropriate for post-intermediate levels.

Both groups in this study were taught by the same teacher. The participants were learning English at a language institute in Talesh, Iran. Their ages were between 22 and 31 with a mean of 25 . All of them were attending the English class twice a week about 90 minutes per session during a semester ( 8 weeks).

\subsection{Materials}

As it was mentioned above, it is the teacher's role to choose suitable materials for students based on their interest and level. Therefore, the teacher selected appropriate clips that were suitable for the learners. Among authentic materials, video clips particularly sitcoms were preferred, since they are more relevant to learners' lives and to real life situations and since they introduce easy but realistic and in-use language. A point of caution should be urged here regarding choosing appropriate materials: some peculiar genres such as horror movies cause frustration in less experienced learners.

The sources of the authentic video clips used in this study were English speaking television sitcoms with the fewest number of distracting scenes such as nude and action. These were probably the best choice because of their simplicity and straightforwardness, their short duration, their development of a plot, the multiplicity of characters, and their presentation of different everyday situations. Moreover, using short television sitcoms, learners who have missed a session could catch up with the class without feeling behind. The films selected for each session depended on what the teacher considered necessary for learners to practice at a given point in the course.

To test the participants' vocabulary retention a test of vocabulary with 20 items was constructed. The test was a multiple-choice paper-pencil test. To calculate the reliability, Kuder-Richardson formula (KR-21) was administered. The reliability estimate for vocabulary test was 0.89 , which means the test was reliable.

\subsection{Procedure}

Although the main focus of study was on the long-term retention of vocabulary, the short-term retention of vocabulary items was also under investigation in this study. After one 8 weeks of instruction, students in both groups took the vocabulary test. The testing session took 20 minutes and there was no penalty for guessing. In order to measure the short-term retention of vocabulary in both control and experimental groups, immediately after finishing the study, the first administration of the vocabulary test (called post-test) was done. To test long-term retention of the studied vocabulary, three weeks after the first administration, the same test (a different version) which called delayed post-test was given to the participants. The method of testing was the same in both administrations. 
The dependent variable in this study was vocabulary retention and the independent variable was an 8-week instruction of vocabulary through different techniques. To compare means of each test (both posttest and delayed post-test) between the groups, $t$ test was used. All of the assumptions for this statistic were met. The alpha level was set to .05

\subsection{Treatment}

This study did not focus on the authenticity of the materials (authenticity of language) as materials in both groups are authentic, but on the authenticity of the way materials were used (authenticity of language use/ authenticity of task), although both are interrelated.

There are two different ways of learning vocabulary: (1) learning vocabulary from context or incidental learning, (2) direct intentional learning (Nemati, 2009). In the treatment group, participants learned vocabulary through watching subtitled videos (incidental learning). First, they watched the video clip with subtitles. During the second viewing, they watched the same movie without subtitles. This activity made them realize that subtitles are not so necessary for understanding the dialogues and storyline. Participants were allowed to take notes of words or expressions from the video clips. Perfect comprehension of video clips was not considered important and it was tried to encourage students to make the most of their partial understanding. However, the teacher's role was not passive. In effect, the teacher's role was a scaffolding one. He provided lexical explanations when students had serious trouble. He also provided necessary pedagogical support for complicated phraseology. The support was removed gradually until they felt independence and comfortable.

On the other hand, in the control group, vocabulary was chosen from the subtitles of the same video clips, but learners underwent intentional learning through traditional methods of vocabulary instruction. Vocabulary instruction in the control group involved different techniques of vocabulary presentation such as
A. Saying the word clearly and write it on the board
B. Getting the class to repeat the word in chorus
C. Translating the word into the students' own language
D. Asking students to translate the word
E. Drawing a picture to show what the word means
F. Giving an English example to show how the word is used
G. Asking questions using the new word

\section{Results}

The current study was done in two steps: in the first step, immediately after the study, a test of vocabulary (called posttest) was administered to both groups. In the next step, after three weeks, the same test (called delayed post-test) was again given to both groups. Descriptive statistics for vocabulary test score of the first administration (post-test), for both control and experimental groups, are presented in Table 1. The means on vocabulary test scores for control and experimental groups are 15.78 and 13.67, respectively. Similar differences in sum scores were also found. There was a minor difference in the standard deviation of two groups (1.896 and 1.970). The two distributions had neither significant skewness nor kurtosis problems.

Table 1. Descriptive statistics of vocabulary test scores for control and experimental groups (post-test)

\begin{tabular}{lrrrrrrrrrr}
\hline & \multicolumn{1}{c}{$\mathrm{N}$} & \multicolumn{2}{c}{ Range } & \multicolumn{1}{c}{ Sum } & \multicolumn{1}{c}{ Mean } & Std. Deviation & Variance & \multicolumn{2}{c}{ Skewness } & \multicolumn{2}{c}{ Kurtosis } \\
\cline { 2 - 10 } & Statistic & Statistic & Statistic & Statistic & Statistic & Statistic & Statistic & Std. Error & Statistic & Std. Error \\
\hline VT.con & 18 & 7 & 284 & 15.78 & 1.896 & 3.595 & -.224 & .536 & -.503 & 1.038 \\
VT.tre & 18 & 7 & 246 & 13.67 & 1.970 & 3.882 & -.150 & .536 & -.739 & 1.038 \\
Valid N & 18 & & & & & & & & & \\
(listwise) & & & & & & & & & & \\
\hline
\end{tabular}

The result of an independent $t$ test of vocabulary test scores (post-test) between control and experimental groups are presented in Table 2: the mean difference between the groups is 2.111 , at a 95\% confidence. It shows that the difference is statistically significant, $t(34)=3.276$, at $p<.05,2$-tailed. However, it should be mentioned that it was the control group that had a better performance. Therefore, the first hypothesis of the study is rejected. This suggests that the students in the control group outperformed the experimental group in short-term retention of vocabulary to a statistically significant degree in the 8-week period of vocabulary instruction, during which they engaged in explicit traditional vocabulary instruction. 


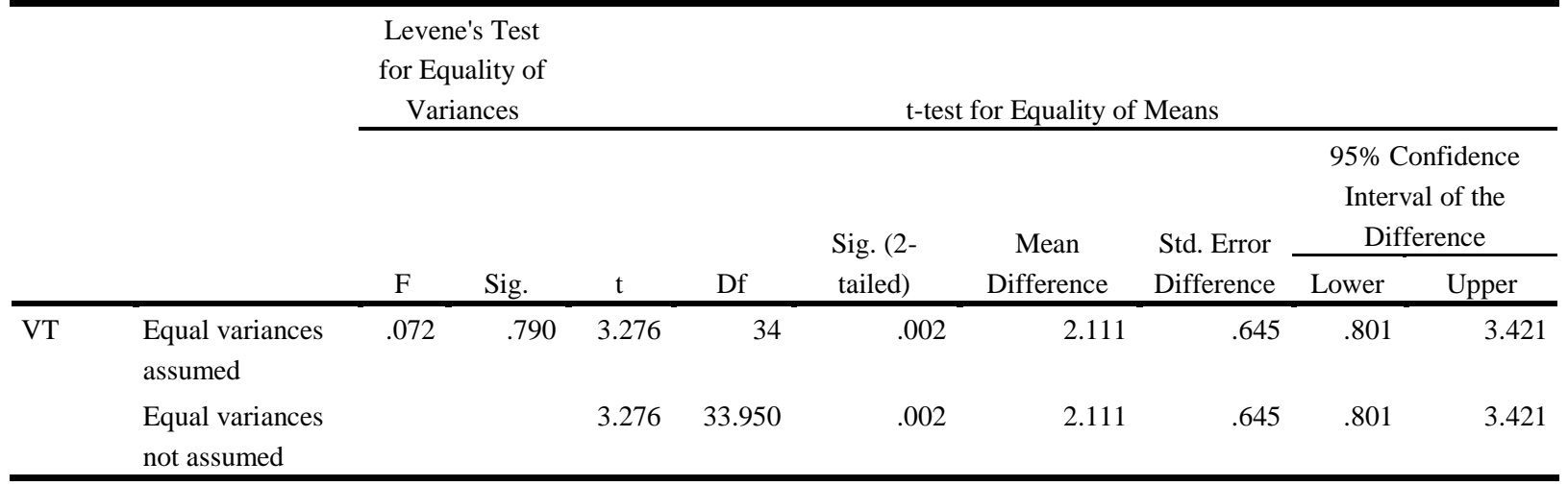

Table 3. depicts the descriptive statistics for vocabulary test score of the second administration (with a three-weak interval), for both control and experimental groups. The means on vocabulary test scores for control and experimental groups are 11.83 and 13.11, respectively. Similar differences in sum scores are also found. However, this time the difference in the standard deviation of two groups is considerable (2.121 and 1.367). The two distributions had neither significant skewness nor kurtosis problems.

Table 3. Descriptive statistics of vocabulary test scores for control and experimental groups (delayed post-test)

\begin{tabular}{|c|c|c|c|c|c|c|c|c|c|c|}
\hline & \multirow{2}{*}{$\frac{\mathrm{N}}{\text { Statistic }}$} & \multirow{2}{*}{$\frac{\text { Range }}{\text { Statistic }}$} & \multirow{2}{*}{$\frac{\text { Sum }}{\text { Statistic }}$} & \multirow{2}{*}{$\frac{\text { Mean }}{\text { Statistic }}$} & \multirow{2}{*}{$\begin{array}{c}\begin{array}{c}\text { Std. } \\
\text { Deviation }\end{array} \\
\text { Statistic }\end{array}$} & \multirow{2}{*}{$\frac{\text { Variance }}{\text { Statistic }}$} & \multicolumn{2}{|c|}{ Skewness } & \multicolumn{2}{|c|}{ Kurtosis } \\
\hline & & & & & & & Statistic & Std. Error & Statistic & Std. Error \\
\hline VT.con & 18 & 7 & 213 & 11.83 & 2.121 & 4.500 & -.296 & .536 & -1.229 & 1.038 \\
\hline VT.tre & 18 & 4 & 236 & 13.11 & 1.367 & 1.869 & -.068 & .536 & -1.434 & 1.038 \\
\hline $\begin{array}{l}\text { Valid N } \\
\text { (listwise) }\end{array}$ & 18 & & & & & & & & & \\
\hline
\end{tabular}

Table 4. shows the result of an independent $t$ test of vocabulary test scores (in the second administration) between control and experimental groups: the mean difference between the groups is -1.278 , at a $95 \%$ confidence. It shows that the difference is statistically significant, $t(34)=-2.148$, at $p<.05$, 2-tailed. However, this time the experimental group that had a slightly better performance. Therefore, the second hypothesis of the study is confirmed. That is, the students in experimental group outperformed control group in long-term retention of vocabulary to a statistically significant degree in the 8-week period of vocabulary instruction, during which they engaged in vocabulary instruction through subtitled videos (implicit instruction).

Table 4. Independent Samples Test between vocabulary test scores for control and experimental groups (delayed post-test)

\begin{tabular}{|c|c|c|c|c|c|c|c|c|c|c|}
\hline & & \multicolumn{2}{|c|}{$\begin{array}{c}\text { Levene's Test for } \\
\text { Equality of } \\
\text { Variances } \\
\end{array}$} & \multicolumn{5}{|c|}{ t-test for Equality of Means } & \multirow{2}{*}{\multicolumn{2}{|c|}{$\begin{array}{c}95 \% \text { Confidence } \\
\text { Interval of the } \\
\text { Difference }\end{array}$}} \\
\hline & & \multirow[b]{2}{*}{$\mathrm{F}$} & \multirow[b]{2}{*}{ Sig. } & \multirow[b]{2}{*}{$\mathrm{t}$} & \multirow[b]{2}{*}{ Df } & \multirow{2}{*}{$\begin{array}{l}\text { Sig. }(2- \\
\text { tailed) }\end{array}$} & \multirow{2}{*}{$\begin{array}{c}\text { Mean } \\
\text { Difference }\end{array}$} & \multirow{2}{*}{$\begin{array}{l}\text { Std. Error } \\
\text { Difference }\end{array}$} & & \\
\hline & & & & & & & & & Lower & Upper \\
\hline \multirow[t]{2}{*}{ VT } & $\begin{array}{l}\text { Equal variances } \\
\text { assumed }\end{array}$ & 6.170 & .018 & -2.148 & 34 & .039 & -1.278 & .595 & -2.487 & -.069 \\
\hline & $\begin{array}{l}\text { Equal variances } \\
\text { not assumed }\end{array}$ & & & -2.148 & 29.045 & .040 & -1.278 & .595 & -2.494 & -.061 \\
\hline
\end{tabular}

The evidence for the superiority of authentic use of authentic materials which in this case was also incidental was conditionally found. That is authentic use of authentic materials is recommended for long-term learning. 


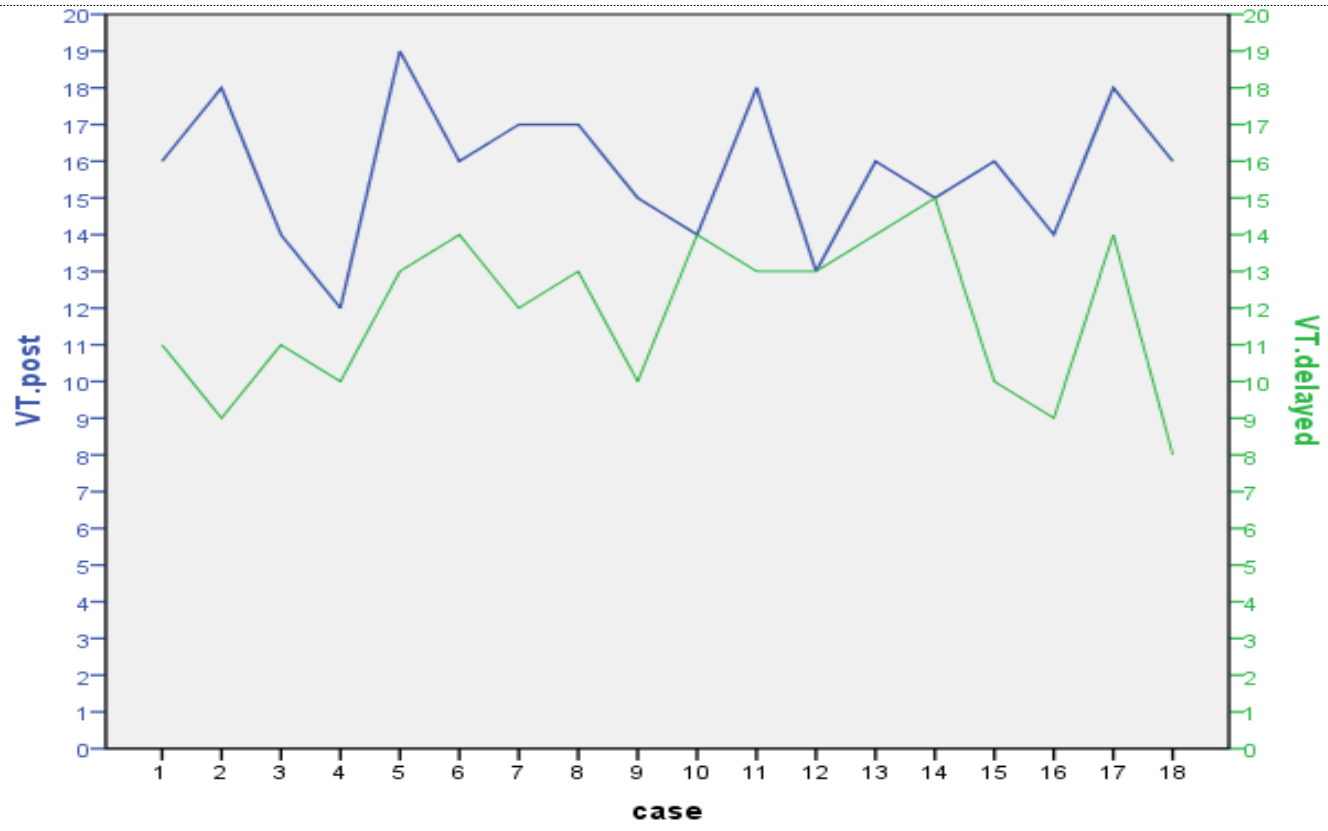

Figure 1. The comparison of each student's vocabulary test (VT) scores in post-test and delayed post-test in the control group

As Figure 1 shows all learners in the control group (except students no. 10, 12 and 14) had a sharp decline in vocabulary test scores in their delayed post-test. That is, long-term retention of vocabulary in the control group was not efficient.

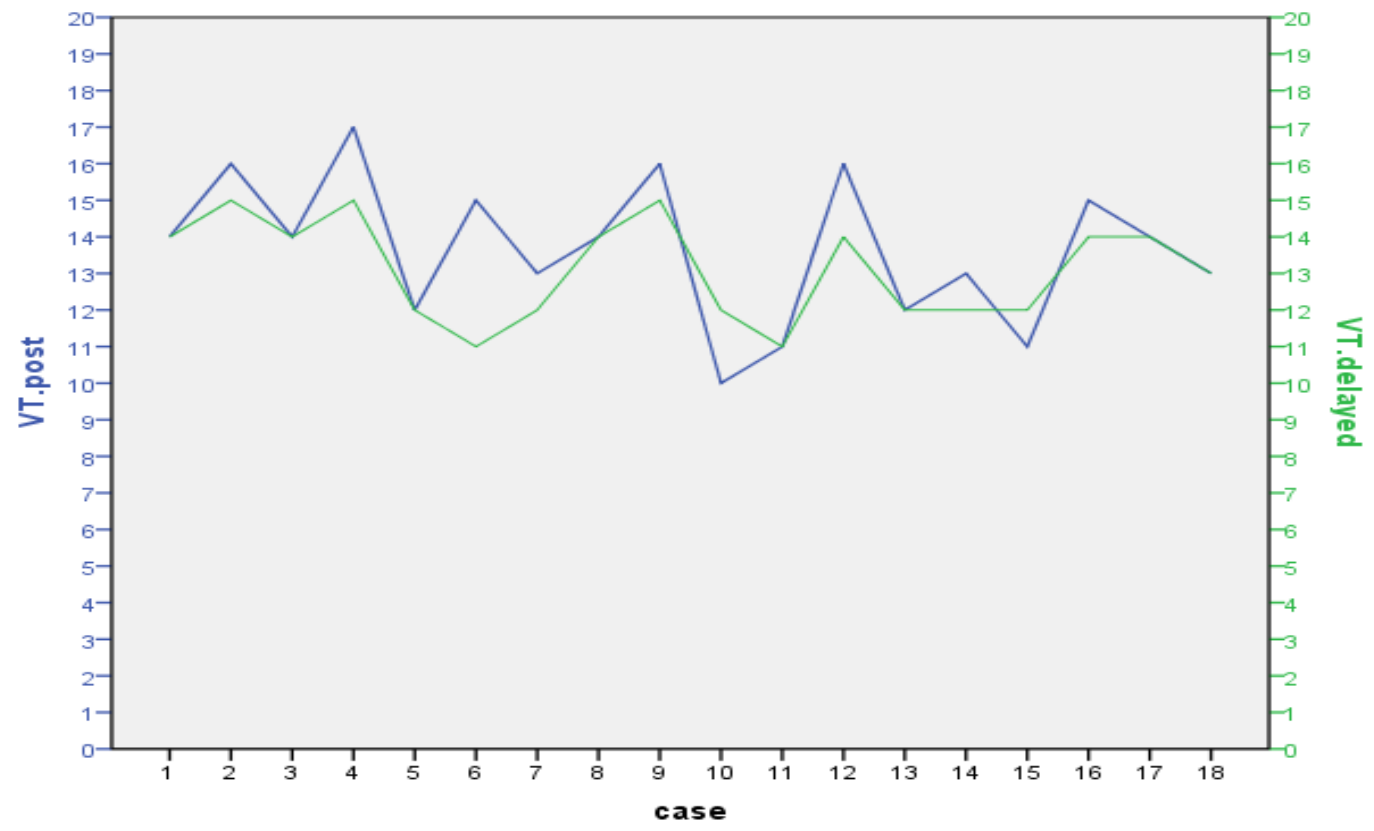

Figure 2. The comparison of each student's vocabulary test (VT) scores in post-test and delayed post-test in the experimental group

Figure 2. indicates that the learners in the experimental group had almost the same vocabulary test scores in their posttest and delayed post-test. That is, long-term retention of vocabulary in the experimental group was supported.

\section{Discussion and Conclusion}

Since feedback from the learners indicated that both groups were highly motivated, the results of the study indicated that using authentic materials, in general, in the classroom, motivates and interests students. In terms of motivation, there was also a difference between the two groups: the authentic use of authentic materials (watching subtitled video clips) motivated students more than the non-authentic use of authentic materials (traditional teaching of the same subtitles).

In both groups, authentic materials were used. However, in the control group materials were taught traditionally. That is, the way the materials were used was not authentic. On the other hand, in the experimental group materials were used in an authentic way, that is, through watching sitcoms. The difference between the groups had a significant effect on the learners' short and long-term retention of vocabulary. Therefore, the results of the present study rejected the first research hypothesis that the learners' short-term vocabulary retention would improve better through subtitled video 
clips. However, the second hypothesis that subtitled video clips improve students' long-term retention of vocabulary is supported.

\subsection{Possible explanation for this finding}

The participants provided with traditional instruction (explicit instruction) were less distracted because they were exposed to less irrelevant information. As a result, they could spend more time on relevant information, and thus learn more vocabulary items. However, the students experiencing authentic use of materials (watching subtitled video clips) were faced with much more distracters including visual and aural ones. In other words, since they were distracted during learning, they learned less vocabulary items. It seems that this difference between both situations would have disappeared if students in the experimental group had watched the video clips a few more times. On the other hand, since the students receiving instruction through authentic use of materials were involved in learning vocabulary through different multimedia features such as visual aids and rich context, and since they were more attracted, motivated and engaged in learning, could have more effective and deep leaning, and as a result could keep vocabulary items in memory for a long time. In other words, the better long-term retention of vocabulary might be because of the integration of visual context, auditiveness, availability of the subtitles and rich context.

Since the participants in the study did not have any further exposure to or practice of the vocabulary items between the first and second administration of the test, nothing expect the way they had learned vocabulary could have contributed to the retention of the vocabulary in the long-term memory.

\subsection{Implications}

Feedback from the learners indicated that since sitcoms were made for native speakers of English, learners appreciated being treated as individuals who were assigned authentic materials. Furthermore, the sense of watching sitcoms is expected to highly increase the motivation and participation of learners, which is necessary in language learning.

It is not argued that watching sub-titled movies are a substitute for traditional vocabulary exercises since, as the study suggests, traditional instruction is much more effective in short-term retention of vocabulary in comparison with teaching vocabulary through subtitled videos. In other words, this study does not discard the traditional explicit teaching of vocabulary, simply because both authentic materials and authentic usage of them are of equal importance.

Video clips are appreciated by learners since they present the culture associated with the target language more efficiently.

The results can be impressive for material developers to have better, more interesting and more authentic of materials that can meet students' need.

It is clear that students need to watch authentic videos especially subtitled ones to complete their language development. It recommends using electronic equipments by language centers for displaying video clips, so that accessibility to authentic materials may result in a better language development and promote students' motivation.

Different methods of presenting new vocabulary to EFL learners, leads to markedly different degrees of vocabulary retention in short and long term periods. Therefore, it is recommended that in order to have a better retention, both short-term and long-term, different methods f leaning vocabulary should be adopted.

Further research on the use of authentic video clips and subtitles are needed to encourage teachers to start using technologies and electronic applications and to make the appropriate use of video and subtitles to enhance the students' long-term vocabulary retention and language learning motivation.

\section{References}

Al Azri, R. H., \& Al-Rashdi, M. H. (2014). The effect of using authentic materials in teaching. International journal of scientific \& technology research, 3(10), 249-254.

Berardo, S. A. (2006). The use of authentic materials in the teaching of reading. The reading matrix, 6(2), 60-69.

Breen, M.P. (1985). Authenticity in the language classroom. Applied Linguistics, 6, 60-70.

Gu, Y. (2003). Vocabulary learning in a second language: Person, task, context and strategies. Teaching English as a Second or Foreign Language, 7(2), 1-25. Retrieved May 5, 2016, from http://www.tesl-ej.org/ej26/a4.html.

Guariento, W., \& Morley, J. (2001). Text and task authenticity in the EFL classroom. ELT Journal, 55(4), $347-353$.

Gulikers, J. T. M., Bastiaens, T. J. \& Martens, R. L. (2005). The surplus value of an authentic learning environment. Computers in Human Behavior. 21, 509-521.

Harji, M. B., Woods, P. C., \& Alavi, Z. K. (2010). The effect of viewing subtitled videos on vocabulary learning. Journal of College Teaching and Learning, 7, 37-42.

Hwang, C. C. (2005). Effective EFL Education through Popular Authentic Materials. Asian EFL Journal, 7(1).90-101.

Lertola, J. (2012). The effect of the subtitling task on vocabulary learning. Retrieved April 11, 2016 from http://isg.urv.es/publicity/isg/publications/trp_4_2012/5-Lertola.pdf

MacDonald, M. N.\& Badger, R. Dasli, M. (2006). Authenticity, culture and language learning. Language and Intercultural Communication, $6(3$ \& 4), 250-26. 
Nemati, A. (2009). Memory vocabulary learning strategies and long-term retention. International Journal of Vocational and Technical Education, 1(2), 14-24.

Peacock, M. (1997). The effect of authentic materials on the motivation of EFL learners. ELT Journal, 51(2), $144-156$.

Richards, J. C., Rodgers, T. C. (2001). Approaches and methods in language teaching (2 ${ }^{\text {nd }}$ Ed). Cambridge: Cambridge University Press.

Sabouri, H., Zohrabi, M. \& Osbouei, Z. K. (2015). The impact of watching English subtitled movies in vocabulary learning in different genders of Iranian EFL learners. International Journal on Studies in English Language and Literature, 3(2), 110-125.

Şarapl1, O. (2011). The use of authentic materials in the second language classrooms: Advantages and disadvantages. Dil Dergisi, 154, 37-43.

Shomoossi, N. \& Ketabi, S. (2007). A critical look at the concept of authenticity. Electronic Journal of Foreign Language Teaching. 4(1). Pp 149-155.

Shrosbree, M. (2008). Digital video in the language classroom. The JALT CALL Journal, 4(1), 75-84.

Taylor, D. (1994). Inauthentic Authenticity or Authentic Inauthenticity? The Electronic Journal for English as a Second Language, 1(2), 1-12. Retrieved May 5, 2016, from http://www.tesl-ej.org/wordpress/issues/volume1/ej02/ej02a1/

Vanderplank, R. 1988. The value of teletext sub-titling in language learning. ELT Journal, 42, 272-281.

Zanon, N. T. (2006). Using subtitles to enhance foreign language learning. Porta Linguarum 6. Retrieved may 6, 2016, from http://www.ugr.es/ portalin/articulos/PL_numero6/talavan.pdf

Zanon, N. T. (2007). Learning vocabulary through authentic video and subtitles. TESOL-SPAIN Newsletter 31, 5-8

Zarei, A. (2009). The effect of bimodal, standard, and reversed subtitling on L2 vocabulary recognition and recall. Pazhuhesh-e Zabanha-ye Khareji, 49, 65-84. 